\title{
Catalytic application of 1-(carboxymethyl)pyridinium iodide on the synthesis of pyranopyrazole derivatives
}

Ahmad Reza Moosavi-Zare, ${ }^{* a}$ Mohammad Ali Zolfigol, ${ }^{\text {b }}$ Rasoul salehi-Moratab, ${ }^{\mathrm{b}}$ Ehsan Noroozizadeh, ${ }^{\mathrm{b}}$

${ }^{a}$ Sayyed Jamaleddin Asadabadi University, Asadabad, 6541835583, I. R. Iran.

${ }^{b}$ Faculty of Chemistry, Bu-Ali Sina University, Hamedan, 6517838683, I. R. Iran.

Corresponding authors: Fax: +98 811 8272404; e-mail addresses: moosavizare@yahoo.com \& mzolfigol@yahoo.com.

\begin{abstract}
:
In this investigation, acetic acid functionalized pyridinium salt, namely 1-(carboxymethyl)pyridinium iodide $\{[\mathrm{cmpy}] \mathrm{I}\}$, has been introduced as reusable catalyst for green, simple and efficient synthesis of 6-amino-4-(4-methoxyphenyl)-5-cyano-3-methyl-1phenyl-1,4-dihydropyrano[2,3-c]pyrazoles by the one-pot tandem four-component condensation reaction of aryl aldehydes with ethyl acetoacetate, malononitrile and hydrazine hydrate at $100{ }^{\circ} \mathrm{C}$ under solvent-free conditions. Additionally, ${ }^{1} \mathrm{H}$ and ${ }^{13} \mathrm{C}$ NMR, mass, $\mathrm{CHN}$ analysis, fourier transform infrared spectroscopy (FT-IR), scanning electron microscope (SEM), thermal gravimetric analysis (TGA), differential thermal gravimetric (DTG), X-ray diffraction analysis (XRD), and calculation of crystallite size and inter planer distance of the catalyst have been investigated.
\end{abstract}

Keywords: Pyranopyrazole, Tandem reaction, 1-(carboxymethyl)pyridinium iodide, solventfree. 


\section{Introduction}

Tandem reaction, as a modern protocol in organic transformations, is a reaction in which several bonds are formed in some sequences without separating of any intermediates, changing reaction conditions and adding reagents. Clean reaction condition, high atomic economy and much complexity in one step are some important advantages of tandem reactions [1-5].

Pyranopyrazoles are interesting class of heterocyclic compounds; they have been used as fungicidal [6], bactericidal [7], vasodilatory [8] and anticancer [9]. They have also reported as pharmaceutical ingredients and biodegradable agrochemicals [10]. Additionally, pyrano[2,3c]pyrazoles have been acted as potential insecticidal [11] and molluscicidal agents [12,13]. Several catalysts have been introduced for the synthesis of pyranopyrazoles, including imidazole [13], per-6-amino-b-cyclodextrin [14], phase transfer catalyst (HDBAC) [15], organocatalysts (MDOs) [16], D,L-Proline [17], hexa decyl tri methyl ammonium bromide (HTMAB) [18], disulfonic acid imidazolium chloroaluminate $\left\{[\mathrm{Dsim}] \mathrm{AlCl}_{4}\right\}$ [19], gamma-Alumina [20], magnetic $\mathrm{Fe}_{3} \mathrm{O}_{4}$ nanoparticles [21] and isonicotinic acid [22]. Therefore, considerable attention has been focused on the development of new protocols for the preparation of these compounds. Recently, we have introduced a new category of ionic liquids and solid salts (with an organic cation), namely sulfonic acid functionalized imidazolium salts (SAFIS) [23-33]. In this class of salts, S-N bond formation in imidazole ring, as five member's heterocyclic compounds, was reported for the first time. These compounds have been successfully applied as catalysts or reagent for the synthesis of bis(indolyl)methanes [23], $N$-sulfonyl imines [24], 1-amidoalkyl-2naphthols [25], various xanthene derivatives [26], 1-carbamatoalkyl-2-naphthols [27], 4, 4'-(arylmethylene)-bis (3-methyl-1-phenyl-1 H-pyrazol-5-ol) s [28], $N$-boc protected amines [29], hexahydroquinolines [30], nitroaromatic compounds [31, 32], 1,2,4,5-tetrasubstituted 
imidazoles [33]. In continuation of our previous projects involving the preparation and applications of acidic ionic liquids and solid salts in organic transformations, we have used 1(carboxymethyl)pyridinium iodide $\{[\mathrm{cmpy}] \mathrm{I}\} \quad$ on the synthesis of 6-amino-4-(4 methoxyphenyl)-5-cyano-3-methyl-1-phenyl-1,4-dihydropyrano[2,3-c]pyrazoles by the one-pot multi-component condensation reaction of arylaldehydes with ethyl acetoacetate, malononitrile and hydrazine hydrate (Scheme 1).

Scheme 1. The preparation of pyranopyrazole derivatives using [cmpy]I.

\section{Experimental}

\subsection{General}

All chemicals were purchased from Merck or Fluka Chemical Companies. The known products were identified by comparison of their melting points and spectral data with those reported in the literature. Progress of the reactions was monitored by TLC using silica gel SIL G/UV 254 plates. The ${ }^{1} \mathrm{H}$ NMR (400 MHz) and ${ }^{13} \mathrm{C}$ NMR (100 MHz) were recorded on a Bruker Avance DPX-250 FT-NMR spectrometer ( $\delta$ in ppm). Infrared spectrum of products was recorded by Perkin Elmer PE-1600-FTIR. Melting points were recorded on a Büchi B-545 apparatus in open capillary tubes. 


\subsection{Procedure for the synthesis of 1 -(carboxymethyl)pyridinium iodide $\{[\mathrm{cmpy}] \mathbf{I}\}$}

A mixture of pyridine $(0.010 \mathrm{~mol})$ and ethyl iodoacetate $(0.010 \mathrm{~mol})$ was stirred and heated at 70 ${ }^{\circ} \mathrm{C}$ for $24 \mathrm{~h}$. After this time, the reaction mixture turned to a dark viscous liquid. The liquid was washed with diethyl ether $(3 \times 30 \mathrm{~mL})$ and dried under vacuum for $2 \mathrm{~h}$. Then, a solution of $\mathrm{HCl}$ $37 \%$ (0.011 mol) was added to prepare liquid and refluxed for $30 \mathrm{~min}$. Finally, the solvent was removed under reduced pressure and the remaining solid was washed with diethyl ether to give the product as a yellowish powder.

\subsection{General procedure for the synthesis of 6-amino-4-(4 -methoxyphenyl)-5-cyano-3- methyl-1-phenyl-1,4- dihydropyrano[2,3-c]pyrazoles}

A mixture of aromatic aldehyde $(2 \mathrm{mmol})$, malononitrile $(0.132 \mathrm{~g}, 2 \mathrm{mmol})$, ethyl acetoacetate (0.26 g, $2 \mathrm{mmol})$ hydrazine hydrate $(2.5 \mathrm{mmol})$ and $\{[\mathrm{cmpy}] \mathrm{I}(10 \mathrm{~mol} \%)$ was added in a $10 \mathrm{~mL}$ round-bottomed flask connected to a reflux condenser, and stirred at $100{ }^{\circ} \mathrm{C}$. After completion of the reaction, as monitored by $\mathrm{TLC}, \mathrm{H}_{2} \mathrm{O}(10 \mathrm{~mL})$ was added to the reaction mixture, stirred and refluxed for $5 \mathrm{~min}$. Then the reaction mixture was filtered and the solvent of the filtrate $\left(\mathrm{H}_{2} \mathrm{O}\right)$ was removed under reduced pressure to separate the catalyst from crude product. The solid residue (crude product) was triturated by a mixture of ethanol and water $(9 / 1)$ to obtain the pure product.

\section{Results and discussion}

1-(carboxymethyl)pyridinium iodide $\{[\mathrm{cmpy}] \mathrm{I}\}$ was synthesized by the reaction of pyridine with ethyl iodoacetate at $70{ }^{\circ} \mathrm{C}$. Then, the product was hydrolysed to give [cmpy]I. The structure of [cmpy]I was confirmed by ${ }^{1} \mathrm{HNMR},{ }^{13} \mathrm{CNMR}$, IR and mass as well as CHN analysis (Scheme 2). 
Scheme 2. The synthesis of 1-(carboxymethyl)pyridinium iodide $\{[\mathrm{cmpy}] \mathrm{I}\}$.

The IR spectrum of [cmpy]I has been shown in Figure S1. The broad peak at $2493-3050 \mathrm{~cm}^{-1}$ can be related to $\mathrm{O}-\mathrm{H}$ stretching of the $\mathrm{COOH}$ group. Also, the peak observed at $1734 \mathrm{~cm}^{-1}$ correspond to vibrational modes of $\mathrm{C}=\mathrm{O}$ bond of the $\mathrm{COOH}$ group. Also, the $\mathrm{C}-\mathrm{H}$ stretching vibrations of pyridine ring in 1-(carboxymethyl)pyridinium iodide observed at $3050 \mathrm{~cm}^{-1}$ and $\mathrm{C}-\mathrm{H}$ bending vibrations of pyridine ring in [cmpy]I appeared at 692 and $888 \mathrm{~cm}^{-1}$. These mentioned peaks clearly confirmed the structure of [cmpy]I.

The structure of [cmpy]I was also studied by NMR studies. The important peak in ${ }^{1} \mathrm{H}$ NMR spectra of the [cmpy]I was related to the acidic hydrogen of $\mathrm{COOH}$ which was observed at 14.06 ppm (Figure S2). Moreover, in ${ }^{13} \mathrm{C}$ NMR spectra of [cmpy]I, the peaks related to methylene group and carbonyl group were observed at 60.56 and $167.66 \mathrm{ppm}$ respectively. The peaks related to pyridine ring were seen at $127.12,146.15$ and $146.74 \mathrm{ppm}$ (Figure S3).

X-ray diffraction analysis (XRD) pattern of 1-(carboxymethyl)pyridinium iodide $\{[\mathrm{cmpy}] \mathrm{I}\}$ was studied in a domain of 0-90 degree (Figure 4). As it is shown at Figure 1, indicates that XRD pattern exhibited diffraction lines of a high crystalline nature at about $z \theta \quad 18.8^{\circ}, 19.6^{\circ}, 23.0^{\circ}$, $24.0^{\circ}, 26.0^{\circ}, 27.4^{\circ}$ and $28.8^{\circ}$. Crystallite size was calculated by Debye-Scherrer's formula given by equation: $\mathrm{D}=\mathrm{K} \lambda /(\beta \cos \theta)$. The crystallite size obtained using this formula was at about 32.49 $\mathrm{nm}$ (for the highest diffraction line at $24.0^{\circ}$ ) and inter planer distance was calculated via the Bragg equation: $\mathrm{dhkl}=\lambda /(2 \sin \theta)$, which obtained $0.3703 \mathrm{~nm}(\lambda: \mathrm{Cu}$ radiation $0.154178 \mathrm{~nm})$. 


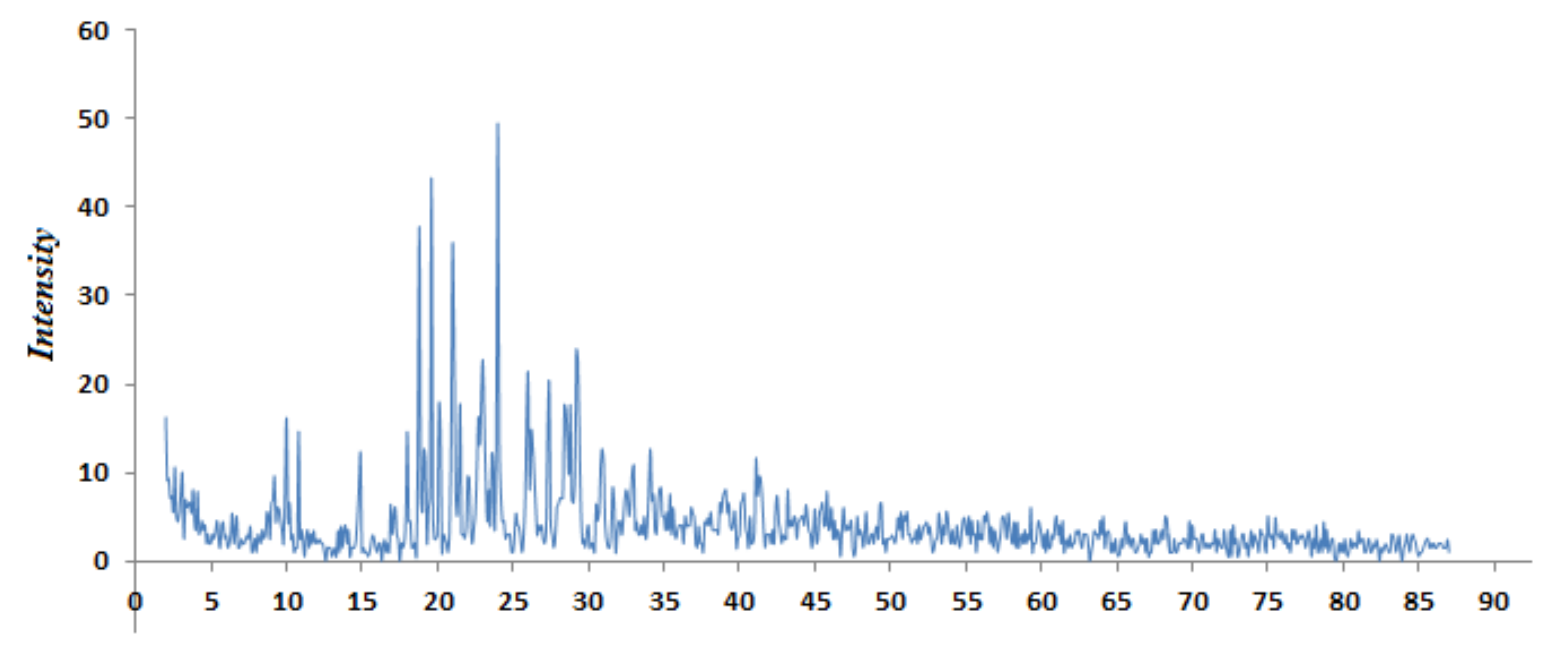

2 Theta

Figure 1. The XRD pattern of 1-(carboxymethyl)pyridinium iodide [cmpy]I.

In another investigation, the scanning electron microscope (SEM) micrographs of the catalyst were studied. The SEM images showed that the particles have not completely agglomerated. Moreover, particles of the catalyst were observed in nano size which is in good agreement with calculated size by Debye-Scherrer's equation (Figure 2).

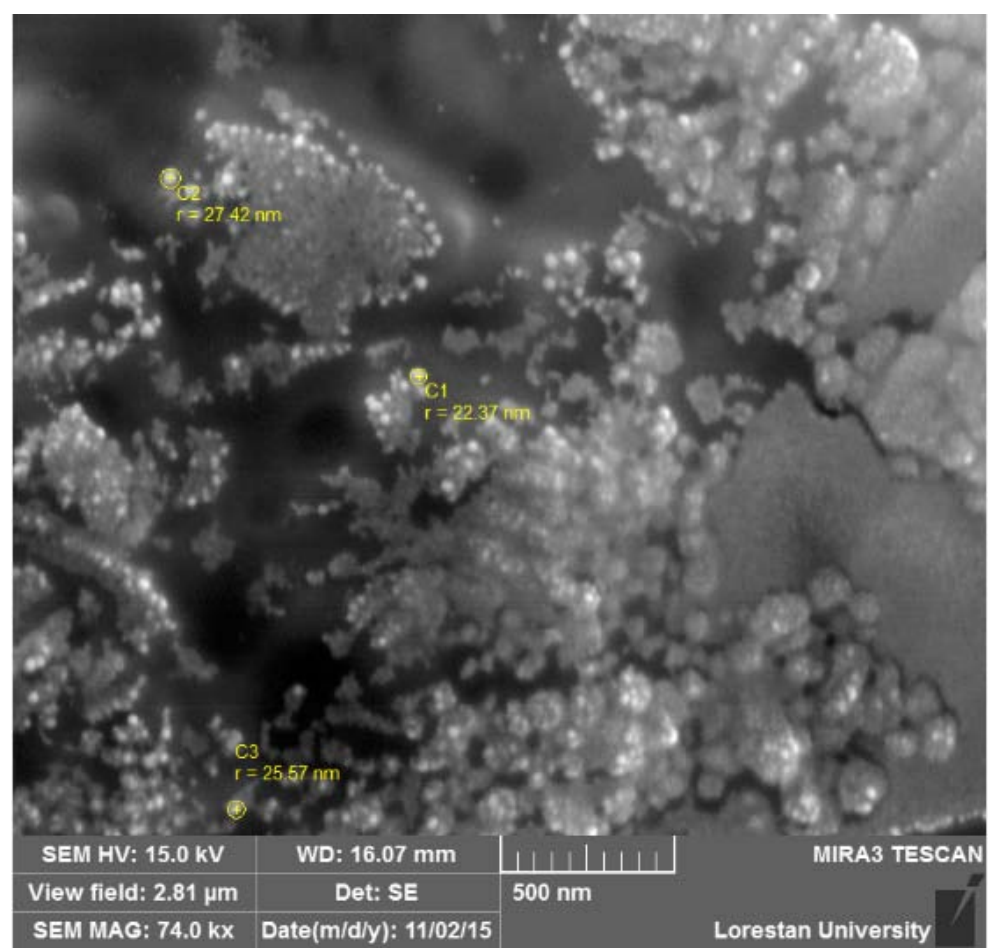

Figure 2. The SEM images of 1-(carboxymethyl)pyridinium iodide [cmpy]I. 
Energy-dispersive X-ray spectroscopy (EDX) from the obtained nanoparticles (Figure 3) provided the presence of the expected elements in the structure of the catalyst, namely carbon, oxygen, nitrogen and iodide. Therefore, the structure of the catalyst was completely confirmed by EDX analyze.

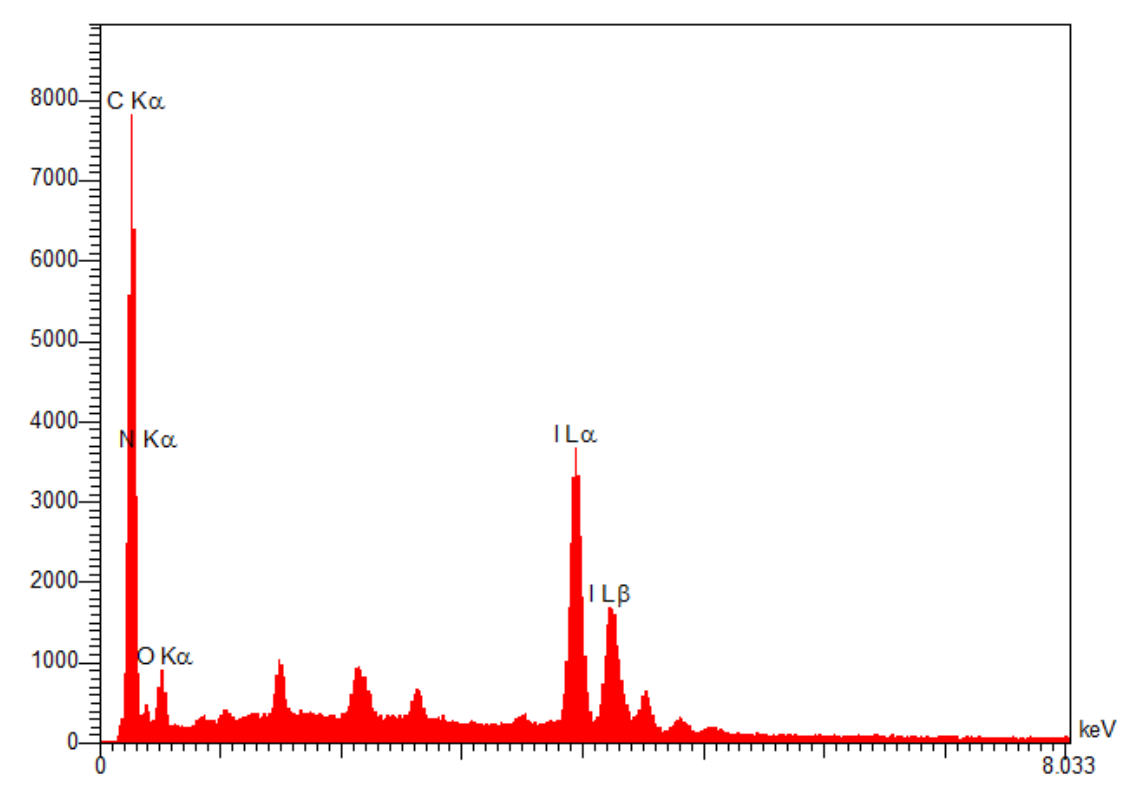

Figure 3. Energy-dispersive X-ray spectroscopy (EDX) of 1-(carboxymethyl)pyridinium iodide [cmpy]I.

Thermal gravimetric analysis (TGA) of the 1-(carboxymethyl)pyridinium iodide $\{[\mathrm{cmpy}] \mathrm{I}\}$ was also studied. The corresponding diagrams are shown in Figure 4. The thermogravimetry (TG) and differential thermal gravimetric (DTG) of the catalyst showed weight losses in two steps. [cmpy]I was decomposed after $286^{\circ} \mathrm{C}$. 
TG \%

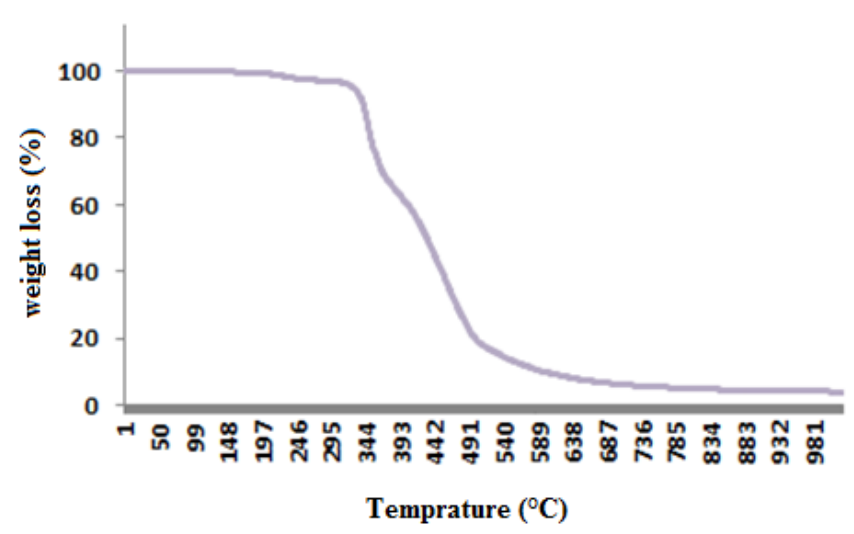

DTG ug/min

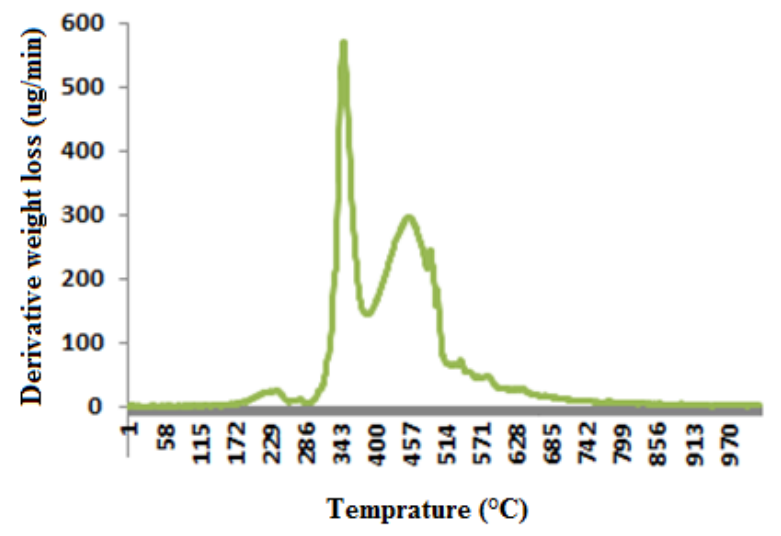

Figure 4. TG/DTG diagrams of 1-(carboxymethyl)pyridinium iodide [cmpy]I.

To optimize the reaction conditions, the condensation between hydrazine hydrate $(2.5 \mathrm{mmol})$ ethyl acetoacetate (2 $\mathrm{mmol})$ malononitrile $(2 \quad \mathrm{mmol})$ and 4-chlorobenzaldehyde $(2 \mathrm{mmol})$, as a model reaction, was investigated in the presence of different amounts of [cmpy]I at range of $60-120{ }^{\circ} \mathrm{C}$ in the absence of solvent (Table 1). As it is shown in Table 1, the reaction was efficiently performed using $10 \mathrm{~mol} \%$ of the catalyst at $100{ }^{\circ} \mathrm{C}$ to give the desired product in high yield within short reaction time (Table 1, entry 3 ). The reaction was also tested at $100{ }^{\circ} \mathrm{C}$ without catalyst under solvent-free conditions in which the reaction did not significantly progress even after long reaction time (Table 1, entry 5). 
Table 1. Effect of different amounts of the catalyst and temperature on the reaction of hydrazine hydrate $(2.5 \mathrm{mmol})$ with ethyl acetoacetate $(2 \mathrm{mmol})$, malononitrile $(2 \mathrm{mmol})$ and 4-chlorobenzaldehyde ( $2 \mathrm{mmol})$ in the absence of solvent.

\begin{tabular}{cccccc}
\hline Entry & $\begin{array}{c}\text { Mol\% of } \\
\text { Catalyst }\end{array}$ & $\begin{array}{c}\text { Temp. } \\
\left({ }^{\circ} \mathrm{C}\right)\end{array}$ & Time (min) & Yield $^{a}(\%)$ \\
\hline 1 & 10 & 60 & 10 & 65 \\
2 & 10 & 80 & 5 & 78 \\
3 & 10 & 100 & 3 & 93 \\
4 & 10 & 120 & 3 & 92 \\
5 & - & 100 & 45 & trace \\
6 & 5 & 100 & 10 & 72 \\
7 & 7 & 100 & 10 & 72 \\
8 & 10 & 100 & 4 & 93 \\
9 & 15 & 100 & 5 & 93 \\
\hline
\end{tabular}

${ }^{a}$ Isolated yield.

In the next step, the model reaction was examined in several solvents using $10 \mathrm{~mol} \%$ of [cmpy]I under reflux conditions. The results are depicted in Table 2. As it is shown in Table 2, indicates that the solvent-free conditions are more effective than solvent conditions.

Table 2. The reaction of hydrazine hydrate $(2.5 \mathrm{mmol})$ with ethyl acetoacetate $(2 \mathrm{mmol})$, malononitrile $(2 \mathrm{mmol})$ and 4-chlorobenzaldehyde $(2 \mathrm{mmol})$ using [cmpy]I $(10 \mathrm{~mol} \%)$ in different solvents $(5 \mathrm{~mL})$ under reflux conditions.

\begin{tabular}{cccc}
\hline Entry & Solvent & Time (min) & Yield $^{a}(\%)$ \\
\hline 1 & - & 3 & 93 \\
2 & $\mathrm{H}_{2} \mathrm{O}$ & 5 & 72 \\
3 & Acetinitrile & 60 & 40 \\
4 & Ethanol & 60 & 45 \\
5 & $\mathrm{CH}_{2} \mathrm{Cl}_{2}$ & 30 & 23 \\
\hline
\end{tabular}

${ }^{a}$ Isolated yield.

To investigate the efficacy and generality of [cmpy]I in the synthesis of 6-amino-4-(4methoxyphenyl)-5-cyano-3-methyl-1-phenyl-1,4-dihydropyrano[2,3-c]pyrazoles, various 
arylaldehydes (including benzaldehyde, and arylaldehydes aldehydes possessing electronreleasing substituents, electron-withdrawing substituents and halogens on their aromatic ring) were reacted with hydrazine hydrate, ethyl acetoacetate and malononitrile under the optimal reaction conditions to obtain the desired products in high yields and in short reaction times. The results are displayed in Table 3. 
Table 3. The preparation of 6-amino-4-(4 -methoxyphenyl)-5-cyano-3-methyl-1-phenyl-1,4dihydropyrano[2,3-c]pyrazoles using [cmpy]I as catalyst at $100^{\circ} \mathrm{C}$.

\begin{tabular}{|c|c|c|c|c|}
\hline Entry & $\begin{array}{l}\text { Product } \\
\end{array}$ & Time (min) & Yield $^{a}(\%)$ & Mp. ${ }^{\circ} \mathrm{C}$ (Lit.) \\
\hline 1 & & 3 & 90 & $\begin{array}{c}261-263 \\
(264-266[19])\end{array}$ \\
\hline 2 & & 4 & 94 & $\begin{array}{c}226-228 \\
(234-236[20])\end{array}$ \\
\hline 3 & & 3 & 86 & $\begin{array}{c}253-255 \\
(261-263[19])\end{array}$ \\
\hline 4 & & 3 & 92 & $\begin{array}{c}198-200(206- \\
208[15])\end{array}$ \\
\hline 5 & & 3 & 91 & $\begin{array}{c}220-222 \\
(250-252[9])\end{array}$ \\
\hline 6 & & 3 & 83 & $229-230$ \\
\hline 7 & & 3 & 95 & $\begin{array}{c}216-218 \\
(244-245[9])\end{array}$ \\
\hline 8 & & 3 & 86 & $\begin{array}{c}198-199 \\
(208-210[21])\end{array}$ \\
\hline
\end{tabular}

${ }^{\mathrm{a}}$ Isolated yield. 
Table 3. (Continued)

\begin{tabular}{|c|c|c|c|c|}
\hline Entry & Product & Time (min) & Yield $^{\mathrm{a}}(\%)$ & Mp. ${ }^{\circ} \mathrm{C}$ (Lit.) \\
\hline 9 & & 3 & 84 & $\begin{array}{c}258-259 \\
(262-264[19])\end{array}$ \\
\hline 10 & & 3 & 84 & $\begin{array}{c}212-214 \\
(208-210[18])\end{array}$ \\
\hline 11 & & 4 & 89 & $\begin{array}{c}242-244 \quad(251- \\
253[15])\end{array}$ \\
\hline 12 & & 3 & 86 & $\begin{array}{c}224-226(223-225 \\
[19])\end{array}$ \\
\hline 13 & & 3 & 87 & $\begin{array}{c}194-196 \\
(210-211[9])\end{array}$ \\
\hline 14 & & 3 & 85 & $\begin{array}{c}242-244(248-250 \\
[9])\end{array}$ \\
\hline
\end{tabular}

${ }^{\mathrm{a}}$ Isolated yield.

In a plausible mechanism, initially, ethyl acetoacetate was activated by [cmpy]I and hydrazine attacked to the carbonyl group of the activated ethyl acetoacetate. Then, loss of $\mathrm{H}_{2} \mathrm{O}$, and intramolecular nucleophillic attack by another $\mathrm{NH}_{2}$ group of hydrazine to the next carbonyl group of ethyl acetoacetate afforded 5-methyl-2,4-dihydro-pyrazol-3-one and removed EtOH. In the next step, by the reaction of aromatic aldehyde, which was activated by [cmpy]I, with malononitrile, cyanoolefin compound was prepared. Finally, by the tandem Michael addition- 
cyclization reaction of 5-methyl-2,4-dihydro-pyrazol-3-one with cyanoolefin compound the desired pyranopyrazole was prepared.

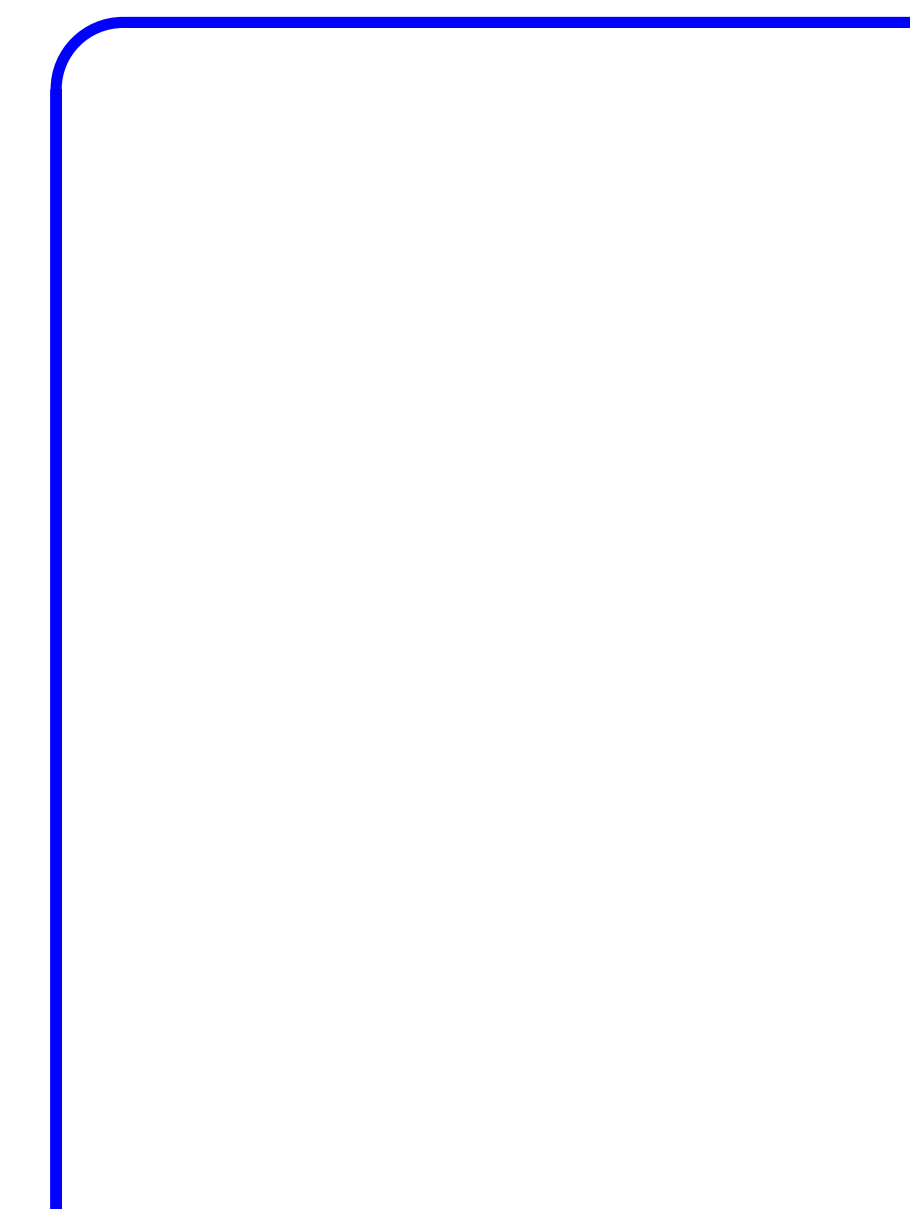

Scheme 3. The plausible mechanism for the synthesis of pyranopyrazoles.

In another investigation, recyclability of the catalyst was examined upon the reaction of hydrazine hydrate $(2.5 \mathrm{mmol})$ with ethyl acetoacetate $(2 \mathrm{mmol})$, malononitrile $(2 \mathrm{mmol})$ and 4-chlorobenzaldehyde ( $2 \mathrm{mmol})$. After completion of the reaction, $\mathrm{H}_{2} \mathrm{O}$ was added to the reaction mixture, stirred and refluxed for $5 \mathrm{~min}$. Then the reaction mixture was filtered and the solvent of the filtrate $\left(\mathrm{H}_{2} \mathrm{O}\right)$ was removed under reduced pressure to separate the catalyst from crude product. Finally, the reused catalyst was used for another reaction. We observed that the catalytic 
activity of the catalyst was restored within the limits of the experimental errors for eight successive runs (Figure 5). In this method, in order to reuse of the catalyst, unreacted hydrazine hydrate is miscible in water and is separated with catalyst.

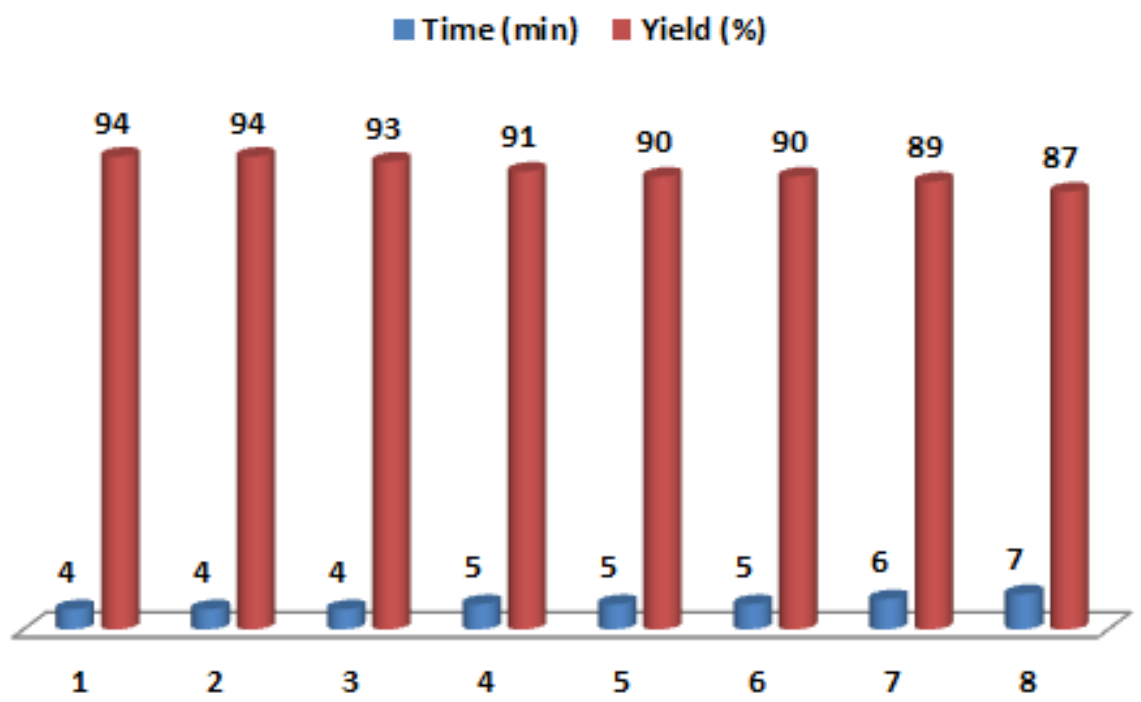

Figure 5. The reaction of hydrazine hydrate with ethyl acetoacetate, malononitrile and 4-chlorobenzaldehyde in the presence of reused [cmpy]I at $100{ }^{\circ} \mathrm{C}$ under solvent-free conditions.

To compare the efficiency of our catalyst with the previous reported catalysts for the preparation of 6-amino-4-(4-methoxyphenyl)-5-cyano-3-methyl-1-phenyl-1,4-dihydropyrano[2,3c]pyrazoles, we have depicted the results of these catalysts to perform the reaction of hydrazine hydrate with ethyl acetoacetate, malononitrile and 4-chlorobenzaldehyde in Table 4. As Table 4 indicates that [cmpy]I has remarkably improved the synthesis of pyranopyrazoles. The reaction times were shorter, and the yields were higher when our catalyst was utilized. 
Table 5. Comparison of the results of the condensation reaction of hydrazine hydrate with ethyl acetoacetate, malononitrile and 4-chlorobenzaldehyde catalyzed by [cmpy]I with those obtained by the recently reported catalysts.

\begin{tabular}{cccccc}
\hline Reaction Condition & Catalyst loading & Time $(\mathrm{min})$ & Yield $^{\mathrm{a}}(\%)$ & TOF $^{\mathrm{b}}\left(\mathrm{min}^{-1}\right)$ & Ref. $^{-1}$ \\
\hline $\mathrm{SiO}_{2} \mathrm{TMG}$, solvent-free, $100^{\circ} \mathrm{C}$ & $10 \mathrm{~mol} \%$ & 20 & 98 & 0.49 & {$[9]$} \\
Gamma-Alumina. $\mathrm{H}_{2} \mathrm{O}$, reflux & $30 \mathrm{~mol} \%$ & 35 & 90 & 0.085 & {$[20]$} \\
HDBAC, EtOH, reflux & $30 \mathrm{~mol} \%$ & 45 & 81 & 0.06 & {$[15]$} \\
Imidazole, $\mathrm{H} 2 \mathrm{O}, 80^{\circ} \mathrm{C}$ & $50 \mathrm{~mol} \%$ & 20 & 90 & 0.09 & {$[13]$} \\
[cmpy]I,solvent-free, $100^{\circ} \mathrm{C}$ & $10 \mathrm{~mol} \%$ & 3 & 86 & 2.86 & $-{ }^{\mathrm{c}}$
\end{tabular}

${ }^{a}$ Isolated yield; ${ }^{b}$ Turn over frequency; ${ }^{c}$ Our work.

\section{Conclusions}

In summary, we have reported the efficient synthesis of 6-amino-4-(4 -methoxyphenyl)-5-cyano-3-methyl-1-phenyl-1,4- dihydropyrano[2,3-c]pyrazoles in the presence of 1-(carboxymethyl)pyridinium iodide $\{[\mathrm{cmpy}] \mathrm{I}\}$ as an acetic acid functionalized pyridinium salt and reusable catalyst. The promising points for the presented methodology are efficiency, generality, high yield, relatively short reaction time, low cost, cleaner reaction profile, ease of product isolation, simplicity, and finally compliance with the green chemistry protocols.

\section{Acknowledgements}

The authors gratefully acknowledge the Bu-Ali Sina University Research Council and Center of Excellence in Development of Environmentally Friendly Methods for Chemical Synthesis (CEDEFMCS) and Sayyed Jamaleddin Asadabadi University for providing support to this work. 


\section{References:}

[1] A. R. Moosavi-Zare, M. A. Zolfigol, O. Khaledian, V. Khakyzadeh, M. D. farahani, M. H. Beyzavi, H. G. Kruger, Chem. Engin. J. 248 (2014) 122-127.

[2] A. R. Moosavi-Zare, M. A. Zolfigol,; O. Khaledian, V. Khakyzadeh, M. D. Farahani, H. G. Kruger, New J. Chem., 38 (2014) 2342-2347.

[3] A. Khazaei, F. Abbasi, A. R. Moosavi-Zare, New J. Chem. 38 (2014) 5287-5292.

[4] A. Khazaei, A. R. Moosavi-Zare, H. Afshar-Hezarkhani, V. Khakyzadeh, RSC Adv. 4 (2014) 32142-32147.

[5] M. A. Zolfigol, A. Khazaei, A. R. Moosavi-Zare, J. Afsar, V. Khakyzadeh; O. Khaledian, J. Chin. Chem. Soc. 62 (2015) 398-295.

[6] A. Feurer, J. Luithle, S. Wirtz, G. Koenig, J. Stasch, E. Stahl, R. Schreiber, F. Wunder, D. Lang, PCT Int. Aool. Wo 2004009589, Baye Healtheare Ag, Germany.

[7] M. N. Nasr, M. M. Gineinah, Arch. Pharm. Med. Chem. 335 (2002) 289.

[8] V. K. Ahluwalia, A. Dahiya and V. Garg, Indian J. Chem. 36B (1997) 88-90.

[9] A. B. Atar, J. T. Kim, K. T. Lim, Y. T. Jeong, Synth. Commun. 44 (2014) 2679-2691.

[10] H. Junek, H. Aigner, Chem. Ber, 106 (1973) 914-921.

[11] E. S. El-Tamany, F. A. El-Shahed, B. H. Mohamed, J. Serb. Chem. Soc. 64 (1999) 9-18.

[12] F. M. Abdelrazek, P. Metz, N. H. Metwally, S. F. El-Mahrouky, Arch. Pharm. 339 (2006) $456-460$.

[13] A. Siddekha, A. Nizam, M. A. Pasha, Spectrochim Acta Part B, 81 (2011) 431.

[14] K. Kanagaraj, K. Pitchumani, Tetrahedron Lett. 51 (2010) 3312-3316.

[15] K. Ablajan, W. Liju, A. Tuoheti, Y. Kelimu, Lett. Org. Chem. 9 (2012) 639-643.

[16] S. Muramulla, C.-G. Zhao, Tetrahedron Lett. 52 (2011) 3905-3908. 
[17] T.-S. Jin, A.-Q. Wang, Z.-L. Cheng, J.-S. Zhang, T.-S. Li, Synth. Commun. 35 (2005) 137143.

[18] S.-B. Guo, S.-X. Wang, J.-T. Li, Synth. Commun.37 (2007) 2111-2120.

[19] A. R. Moosavi-Zare, M. A. Zolfigol, E. Noroozizadeh, M. Tavasoli, V. Khakyzadeh, A. Zare, New J. Chem. 37 (2013) 4089-4094.

[20] H. Mecadon, M. R. Rohman, M. Rajbangshi, B. Myrboh, Tetrahedron Lett. 52 (2011) 25232525.

[21] M. A. E. Aleem, A. A. El-Remaily, Tetrahedron 70 (2014) 2971-2975.

[22] M. A. Zolfigol, M. Tavasoli, A. R. Moosavi-Zare, P. Moosavi, H. G. Kruger, M. Shiri, V. Khakyzadeh, RSC Adv. 3 (2013) 25681-25685.

[23] M. A. Zolfigol, A. Khazaei, A. R. Moosavi-Zare, A. Zare, Org. Prep. Proced. Int. 42 (2010) 95-102.

[24] M. A. Zolfigol, A. Khazaei, A. R. Moosavi-Zare, A. Zare, J. Iran. Chem. Soc. 7 (2010) 646651.

[25] M. A. Zolfigol, A. Khazaei, A. R. Moosavi-Zare, A. Zare, V. Khakyzadeh, Appl. Catal A Gen. 400 (2011) 70-81.

[26] M. A. Zolfigol, V. Khakyzadeh, A. R. Moosavi-Zare, A. Zare, S. B. Azimi, Z. Asgari, A. Hasaninejad, C. R. Chim. 15 (2012) 719-736.

[27] A. Zare, T. Yousofi, A. R. Moosavi-Zare, RSC. Adv. 2 (2012) 7988-7991.

[28] A. Khazaei, M. A. Zolfigol, A. R. Moosavi-Zare, Z. Asgari, M. Shekouhy, A. Zare, Hasaninejad, A. RSC. Adv. 2 (2012) 8010-8013.

[29] M. A. Zolfigol, V. Khakyzadeh, A. R. Moosavi-Zare, G. Chehardoli, F. Derakhshan-Panah, A. Zare, O. Khaledian, Scientia Iranica: Trans. C: Chem. Chem. Engin. 19 (2012) 1584-1590. 
[30] A. Zare, F. Abi, A. R. Moosavi-Zare, M. H. Beyzavi, M. A. Zolfigol, J. Mol. Liq. 178 (2013) 113-121.

[31] A. Khazaei, M. A. Zolfigol, A. R. Moosavi-Zare, A. Zare, Scientia Iranica: Trans. C: Chem. Chem. Engin. 17 (2010) 31-36.

[32] M. A. Zolfigol, A. Khazaei, A. R. Moosavi-Zare, A. Zare, H. G. Kruger, Z. Asgari, V. Khakyzadeh, M. Kazem-Rostami, J. Org. Chem. 77 (2012) 3640-3645.

[33] M. A. Zolfigol, A. Khazaei, A. R. Moosavi-Zare, A. Zare, Z. Asgari, V. Khakyzadeh, A. Hasaninejad, J. Ind. Engin. Chem. 19 (2013) 721-726. 


\section{Graphical Abstract}

Catalytic application of 1-(carboxymethyl)pyridinium iodide on the synthesis

\section{of pyranopyrazole derivatives}

Ahmad Reza Moosavi-Zare,* Mohammad Ali Zolfigol,* Rasool salehi, Ehsan Noroozizadeh,

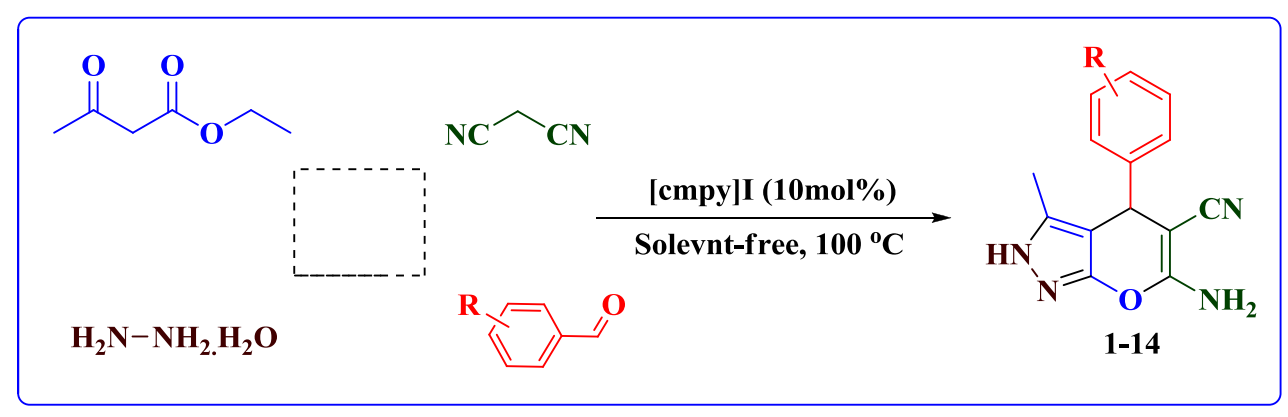

